\title{
Aging is associated with changes in allopregnanolone concentrations in brain, endocrine glands and serum in male rats
}

\author{
F Bernardi, C Salvestroni, E Casarosa ${ }^{1}$, R E Nappi ${ }^{2}$, A Lanzone ${ }^{3}$, S Luisi, R H Purdy ${ }^{4}$, F Petraglia ${ }^{5}$ and \\ A R Genazzani \\ Department of Obstetrics and Gynecology, University of Pisa, Pisa, Italy, ${ }^{1}$ CNR, Endocrine Research Unit, Pisa, Italy, ${ }^{2}$ Department of Obstetrics and \\ Gynecology, University of Pavia, Pavia, Italy, ${ }^{3}$ Obstetrics and Gynecology, Oasi, Troina, Italy, ${ }^{4}$ Department of Psychiatry, Veteran Administration \\ Hospital, San Diego, California, USA and ${ }^{5}$ Department of Surgical Science, University of Udine, Udine, Italy \\ (Correspondence should be addressed to A R Genazzani, Department of Obstetrics and Gynecology, University of Pisa, 56100 Pisa, Italy)
}

\begin{abstract}
Objective: Allopregnanolone is a potent neuroactive steroid hormone produced in the brain and in peripheral endocrine glands. The present study investigated possible age-related variations in allopregnanolone content in brain areas, endocrine glands and serum of male rats.

Design: Wistar male rats were categorized into 5 groups (6 rats in each) according to age: 6, 12, 16, 18 and 20 months respectively.

Methods: Allopregnanolone content in acidic homogenates of brain cortex, hypothalamus, pituitary, adrenals and gonads was measured by a specific radioimmunoassay. Serum allopregnanolone, corticosterone and testosterone were also assayed by radioimmunoassay.

Results: Brain cortex allopregnanolone content decreased significantly with age, while hypothalamic allopregnanolone content remained constant until 18 months and increased significantly at 20 months. Pituitary content showed a significant age-related reduction. Adrenal allopregnanolone content remained constant until 18 months, and was significantly higher at 20 months. Testis and serum allopregnanolone contents showed significant age-related increases. Serum testosterone levels showed an age-related decrease, while no age-related variation in serum corticosterone was found.

Conclusions: The present study showed a significant impact of aging on allopregnanolone contents in brain, endocrine glands and serum, showing an age-related decrease in brain cortex and pituitary, and an age-related increase in testes, adrenals and serum.
\end{abstract}

European Journal of Endocrinology 138 316-321

\section{Introduction}

Neuroactive steroids are substances synthesized in the brain, either de novo from cholesterol or by in situ metabolism of blood-borne precursors. Chemically characterized in other tissues but also synthesized within the brain, neurosteroids participate in the regulation of brain function (1-3). Among them, $3 \alpha$-hydroxy-5 $\alpha$-pregnan20 -one (allopregnanolone) is one of the best represented and one of the most potent. Allopregnanolone may act as an endogenous ligand of GABA-A receptors and has anxiolytic-sedative effects in rats under physiological conditions such as stress or pregnancy $(4,5)$. An ovarian contribution to plasma and brain allopregnanolone concentration is indicated by the higher levels observed in female rats compared with age-related males and by the decrease in plasma levels after ovariectomy (6). An adrenal origin of allopregnanolone in both male and female rats has also been shown (6).

A correlation between allopregnanolone and reproductive life has been suggested. Rat hypothalamic and hippocampal contents of allopregnanolone show significant changes during the estrous cycle $(7,8)$. No data on brain allopregnanolone content are available in aged rats. The observation that allopregnanolone modulation of the stress response is impaired in aged rats (8) and that the plasma levels of other neuroactive steroids, such as dehydroepiandrostenedione (DHEA) undergo changes with aging in rats and in man (9-11), led us to investigate possible age-related variations in allopregnanolone levels in different brain areas, endocrine glands, and serum of male rats.

\section{Materials and methods}

Wistar male rats ( 5 groups of 6 rats each) were grouped according to their age: $6,12,16,18$ and 20 months respectively. All rats were kept in the laboratory for at least a week before being killed; they were exposed to $12 \mathrm{~h}$ light/day and food and water were available $a d$ libitum. Animals were killed by decapitation. 
Brain cortex, hypothalamus, pituitary, adrenals and testes were quickly removed, weighed and homogenized in ice-cold $50 \%$ aqueous methanol containing $1 \%$ acetic acid with 3000 d.p.m. tritium-labeled steroid as internal recovery standard. The homogenate was centrifuged at 1200 r.p.m. for $15 \mathrm{~min}$ at $4^{\circ} \mathrm{C}$. Blood was collected in plastic tubes, centrifuged at 3500 r.p.m. for $10 \mathrm{~min}$, and the serum was stored at $-20^{\circ} \mathrm{C}$ until assay. The supernatants of the tissue homogenates and serum were passed through a C-18 Sep-Pak cartridge, previously equilibrated with the homogenizing buffer. The cartridge was sequentially washed with homogenizing buffer, $50 \%$ aqueous methanol, and the unconjugated steroid fraction was eluted with absolute methanol and brought to dryness under nitrogen. Analytical grade solvents were purchased from Merck (Darmstadt, Germany); C-18 Sep-Pak cartridges were obtained from Waters Corporation (Milford, MA, USA). Allopregnanolone contents were measured by radioimmunoassay (RIA). Standard allopregnanolone was purchased from Sigma Chemical Co. (St Louis, MO, USA) and pregnan-3 $\alpha$-ol-2o-one, $5 \alpha-\left[9,11,12-{ }^{3} \mathrm{H}(\mathrm{N})\right] \quad(45 \mathrm{Ci} / \mathrm{mmol})$ was from Amersham (Little Chalfont, Bucks, UK). Polyclonal antisera raised in sheep against allopregnanolone carboxymethyl ether coupled to bovine serum albumin (kindly provided by Dr Purdy) have been employed.

For further validation of the assay procedure, we used an internal recovery standard of tritium-labeled allopregnanolone for each sample; data were corrected for procedural loss. Serum samples containing an internal recovery standard of $\left[{ }^{3} \mathrm{H}\right]$ allopregnanolone were extracted according to the same procedure.

The antiserum was employed at a final working dilution of 1:4000, determined from its ability to bind $50 \mathrm{pg}$ labeled steroid. The cross-reactivity of the sheep antisera against $3 \alpha$-hydroxy-20-oxo- $5 \alpha$-pregnan- $11 \alpha$-yl carboxymethyl ether coupled to bovine serum albumin was determined by testing the ability of various structurally similar compounds to displace tritiated allopregnanolone from the antibody. The only significant cross-reactivity occurred with $3 \alpha$-hydroxy- $5 \beta$-pregnan20-one (Table 1), which is not found in appreciable concentration in rat tissues where $5 \alpha$-reductase activity predominates.

The sensitivity of the assay was $15 \mathrm{pg} / \mathrm{ml}$ and the losses during sample processing were determined as recovery of the tracer $\left(1500\right.$ d.p.m. $\left[{ }^{3} \mathrm{H}\right]$ allopregnanolone) added to analyzed serum; the average recovery was $85.5 \pm 5.7 \%$ (mean \pm s.e.m.) and the intra- and interassay coefficients of variation were $7 \%$ and $9 \%$ respectively.

Serum corticosterone (ICN Biomedicals Inc., Irvine, CA, USA) and testosterone (Radim SpA, Pomezia, Italy) were assayed by radioimmunoassay using trade kits. For corticosterone the assay sensitivity was $25 \mathrm{pg} / \mathrm{ml}$ and the intra- and interassay coefficients of variation were $5.8 \%$ and $7.5 \%$ respectively; for testosterone the
Table 1 Cross-reactivities of the sheep antisera against $3 \alpha$-hydroxy-20-oxo- $5 \alpha$-pregnan- $11 \alpha$-yl carboxymethyl ether coupled to bovine serum albumin.

\begin{tabular}{lc}
\hline Steroid & Cross-reactivity (\%) \\
\hline $3 \alpha$-Hydroxy-5 $\alpha$-pregnan-20-one & 100.00 \\
Pregn-4-ene-3,20-dione & 0.70 \\
$5 \alpha$-Pregnane-3,20-dione & 0.10 \\
$5 \beta$-Pregnane-3,20-dione & 0.10 \\
$3 \alpha$-Hydroxy-5 $\beta$-pregnan-20-one & 6.50 \\
20 $\beta$-Hydroxy-5 $\alpha$-pregnan-3-one & 0.10 \\
$3 \beta$-Hydroxy-5 $\alpha$-pregnan-20-one & 0.05 \\
$3 \beta$-Hydroxy-5 $\beta$-pregnan-20-one & 0.01 \\
$5 \alpha$-Pregnane-3 $\alpha, 20 \alpha$-diol & 0.10 \\
$5 \alpha$-Pregnane-3 $\beta, 20 \alpha$-diol & 0.01 \\
$5 \beta$-Pregnane-3 $\alpha, 20 \alpha$-diol & 0.03 \\
\hline
\end{tabular}

The following steroids have a cross-reactivity $<0.001 \%$ : $3 \alpha-$ hydroxy-5 $\alpha, 17 \alpha$-pregnan-20-one, 3 $\beta$-hydroxypregnan-5-en20-one, $3 \alpha$-11 $\beta$-dihydroxy-5 $\alpha$-pregnan-20-one, $3 \alpha$-20 $\beta$-dihydroxy-5 $\alpha$-pregnane, $3 \alpha$-21-dihydroxy-5 $\alpha$-pregnan-20-one 21 acetate, $3 \beta-20 \beta$-dihydroxy-5 $\alpha$-pregnane, $3 \alpha$-21-dihydroxy$5 \alpha$-pregnan-20-one, $3 \alpha$-17 $\alpha$-dihydroxy-5 $\alpha$-pregnan-20-one, $3 \beta$-17 $\alpha$-dihydroxy-5 $\alpha$-pregnan-20-one, $3 \beta$-21-dihydroxy-5 $\alpha$ pregnan-20-one, $3 \beta$-21-dihydroxy-5 $\beta$-pregnan-20-one, $17 \alpha$ hydroxy-4-pregnane-3,20-dione, androst-4-ene,3,17-dione, dehydroepiandrosterone, testosterone, 11 1 -hydroxytestosterone, $5 \alpha$-dihydrotestosterone, cortisol, corticosterone, estrone, estradiol, estriol.

assay sensitivity was $17 \mathrm{pg} / \mathrm{ml}$ and the intra- and interassay coefficients of variation were $4.2 \%$ and $6.6 \%$ respectively.

Measurements were made in duplicate on two dilutions of each purified sample and all data were expressed as $\mathrm{ng} / \mathrm{g}$ for tissue contents or $\mathrm{ng} / \mathrm{ml}$ for serum levels (mean \pm s.e.m.). Statistical analysis was performed using Dunnett's test for multiple comparisons.

\section{Results}

Brain cortex allopregnanolone content showed a significant progressive decrease with age $(6.30 \pm 0.32 \mathrm{ng} /$ $\mathrm{g}$ at 6 months vs $3.00 \pm 0.20 \mathrm{ng} / \mathrm{g}$ at 20 months; $P<0.001$ at 16,18 and 20 months vs 6 months), while hypothalamic allopregnanolone content was quite constant until 18 months and increased significantly at 20 months $(1.95 \pm 0.05 \mathrm{ng} / \mathrm{g} ; P<0.01$ vs 6 months $)$ (Fig. 1). Pituitary allopregnanolone showed a statistically age-related significant reduction $(2.98 \pm 0.12 \mathrm{ng} /$ $\mathrm{g}$ at 6 months vs $0.75 \pm 0.03 \mathrm{ng} / \mathrm{g}$ at 20 months; $P<0.001$ at $12,16,18$ and 20 months vs 6 months) (Fig. 2). Allopregnanolone content in the adrenal gland was quite constant until 18 months, and increased significantly at 20 months $(52.9 \pm 0.3 \mathrm{ng} / \mathrm{g} ; P<0.01$ vs 6 months) (Fig. 2). The content of allopregnanolone in the testis showed a clear age-related variation, increasing gradually from $0.062 \pm 0.007 \mathrm{ng} / \mathrm{g}$ at 6 months to $0.35 \pm 0.03 \mathrm{ng} / \mathrm{g}$ at 20 months $(P<0.001$ at 16,18 and 20 months vs 6 months) (Fig. 2). 
Serum allopregnanolone was detectable in all rats and significantly and progressively increased with age (from $0.23 \pm 0.05 \mathrm{ng} / \mathrm{ml}$ at 6 months to $0.31 \pm$ $0.03 \mathrm{ng} / \mathrm{ml}$ at 18 months and $0.42 \pm 0.06 \mathrm{ng} / \mathrm{ml}$ at 20 months; $P<0.001)$. No significant age-related variation in serum corticosterone was found. On the other hand, serum testosterone levels showed a significant age-related progressive decrease (from $2.00 \pm 0.08 \mathrm{ng} / \mathrm{ml}$ at 6 months to $0.81 \pm 0.06 \mathrm{ng} / \mathrm{ml}$ at 20 months; $P<0.001$ at 16,18 and 20 months vs 6 months) (Fig. 3).
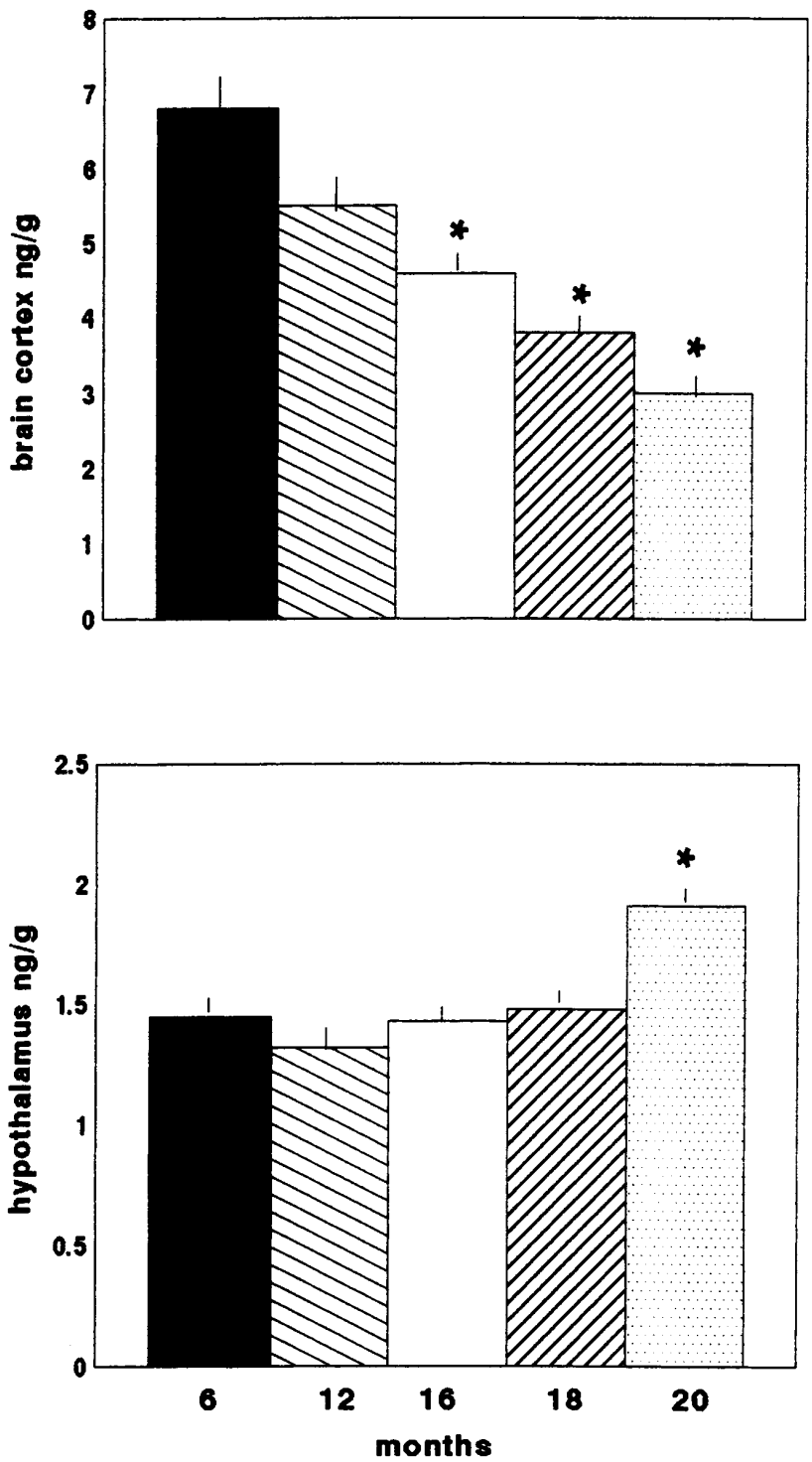

Figure 1 Mean \pm S.E.M. age-related decrease in allopregnanolone content in the cortex $\left(y=-107.224 x+2955.193, r^{2}=0.778\right.$,

${ }^{*} P<0.001$ vs 6 months) and increase in allopregnanolone content in the hypothalamus at 20 months ( ${ }^{*} P<0.01$ vs 6 months) in male rats.
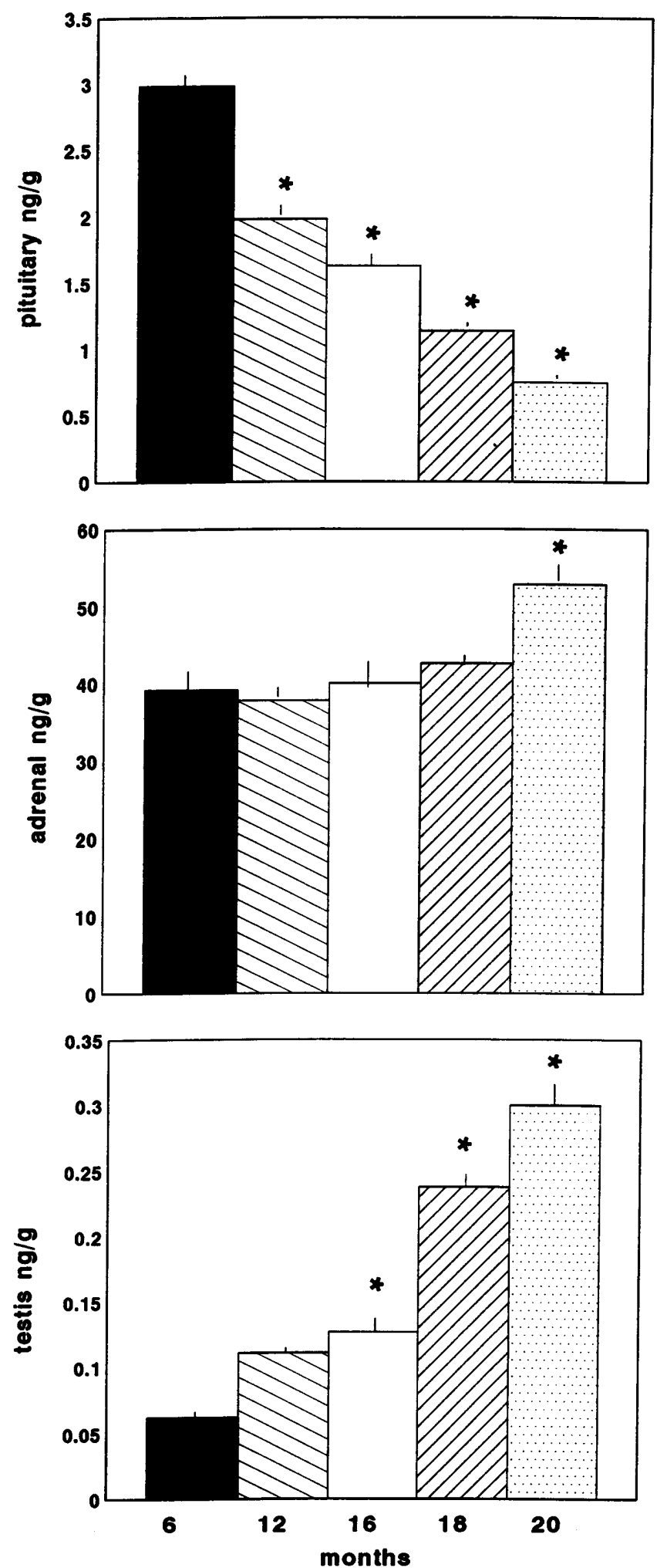

Figure 2 Mean \pm S.E.M. age-related changes in allopregnanolone content in the pituitary $\left(y=-38.372 x+977.961, r^{2}=0.906\right.$, ${ }^{*} P<0.001$ vs 6 months), adrenal $(y=44.942 x+667.974$ $r^{2}=0.151,{ }^{*} P<0.01$ vs 6 months) and testis $(y=12.459 x-$ $59.72, r^{2}=0.605,{ }^{*} P<0.001$ vs 6 months) in male rats. 



Figure 3 Mean \pm S.E.M. age-related changes in the serum concentrations of allopregnanolone $\left(y=0.037 x+0.44, r^{2}=0.434\right.$,

${ }^{*} P<0.001$ vs 6 months), corticosterone (no significant age-related changes) and testosterone $\left(y=-34.322 x+907.875, r^{2}=0.915\right.$, ${ }^{*} P<0.001$ vs 6 months) in male rats.

\section{Discussion}

The present study is the first to describe age-related changes in allopregnanolone content in various cerebral areas and endocrine glands in male rats. Data concerning allopregnanolone levels in some rat brain areas according to stress and the stage of the estrous cycle have been reported previously $(8,12,13)$ but allopregnanolone variations with age have never been described.

In this study allopregnanolone evaluation was performed by radioimmunological assay. It has been reported that radioimmunological methods are not sufficiently specific for assessing neurosteroid content, and that high performance liquid chromatography coupled with gas chromatography-mass fragmentography is a more reliable method for these studies (14). However, in the present study the use of new more specific antisera appears to be a satisfactory alternative to the latter method, which is unsuitable for routine allopregnanolone assessment.

The present data show a significant decrease in brain cortex allopregnanolone content starting at 16 months of age, while an increase in hypothalamic allopregnanolone content at 20 months is observed. Allopregnanolone contents in brain cortex and hypothalamus of adult male rats are similar to those described in the literature $(12,13)$. The present data and the increase in cerebral allopregnanolone content under stressful conditions suggest that the stressinduced increase and the age-related decrease in brain allopregnanolone may have important behavioral and/or neuroendocrine consequences $(12,13)$. It has been hypothesized that the stress-induced increase in allopregnanolone results in a diminished release of corticotropin releasing factor and adrenocorticotropin (ACTH)/corticosterone, determining a novel feedback loop which decreases the activity of the hypothalamus-pituitary-adrenal axis under stress (12). The age-related decrease of hypothalamuspituitary-adrenal activity in response to stress may occur because of the age-related decrease in cerebral allopregnanolone content.

A significant reduction in hypothalamic allopregnanolone content at proestrus also suggests a putative role of neurosteroids in the modulation of the ovulatory process (8).

It has been demonstrated that the anterior pituitary of female rats metabolizes progesterone to allopregnanolone and that this process is altered during reproductive senescence in female rats (15). No data on age-related variations in allopregnanolone pituitary content in male rats are available and the present study shows that pituitary allopregnanolone concentration in male rats significantly decreases from 6 months to 20 months of age.

The $5 \alpha$-reductase- $3 \alpha$-hydroxysteroid-dehydrogenase system is responsible for the conversion of progesterone 
into $5 \alpha$-pregnan-3 $\alpha$-ol-20-dione and then into $5 \alpha$ pregnan-3 $\alpha$-ol-20-one. Rat adrenal glands express a $5 \alpha$-steroid reductase and produce allopregnanolone in quantities similar to those secreted by the rat ovary (16). The results of the present study concerning adrenal allopregnanolone content in adult male rats are consistent with previous data (6), showing a significant increase in allopregnanolone adrenal content in aged rats.

The synthesis of pregnane compounds in the rat female ovary has been clearly demonstrated (17), while previous studies considered allopregnanolone undetectable in the testis (6). In contrast, the specific radioimmunoassay used in the present study was able to detect allopregnanolone in the testis, showing an increasing concentration from 6 to 20 months of age. Serum allopregnanolone levels paralleled the agerelated increase in adrenal and testis allopregnanolone contents. These findings support the hypothesis that the adrenals and testes may be the main sources of circulating allopregnanolone in male rats (6).

In the present study no significant age-related variations in serum corticosterone were found, while a significant age-related progressive decrease in testosterone was detected, thus confirming previously reported data $(18,19)$. It has been hypothesized that an increase in adrenal sensitivity to ACTH is responsible for the maintenance of corticosterone levels in the presence of diminished ACTH levels in aged rats (18).

The opposite variations in allopregnanolone contents in brain cortex and serum suggest that the concentration of allopregnanolone in the brain is independent of circulating allopregnanolone. It has been suggested that the main site of formation of cerebral allopregnanolone is the brain itself, although serum progesterone constitutes the major precursor for allopregnanolone synthesis in the brain $(6,12)$. The higher cerebral allopregnanolone content observed in young rats may be a consequence of higher levels of $5 \alpha$-reductase activity. In situ hybridization studies have shown that $5 \alpha$ reductase mRNA is highly expressed in the pre- and early postnatal rat central nervous system, while it is expressed at low levels rather uniformly in the adult rat brain (20). No data are available on enzyme activity in aged rats.

The discussion remains open on the possible target of brain allopregnanolone. The increased synthesis of allopregnanolone in rat brain following acute stress suggested that this steroid may play a role as an endogenous stress-protective compound (21). Pretreatment with high doses of allopregnanolone significantly decreased corticotropin-releasing hormone-induced behavioral manifestations of stress and anxiety, indicating an anxiolytic, sedative-hypnotic and anti-aggressive effect similar to that produced by the benzodiazepines (22). A putative inhibitory role of allopregnanolone on the response of corticosterone to stress has been hypothesized. In fact, it has been reported that in aged rats treatment with antiserum raised against allopregnanolone failed to modify serum corticosterone levels following acute physical stress, as it does in adult rats (23). Therefore, it is possible that with advancing age neurosteroids lose part of their activity in the control of the hypothalamus-pituitary-adrenal axis (11). The significant age-related decrease in brain and pituitary allopregnanolone concentration observed in the present study supports this hypothesis.

In addition, the age-related decrease in allopregnanolone concentration in the brain may have an impact on stress, memory, anxiety and sexual behavior. These functions, typically altered in aged rats, may correspond to a variety of nervous and affective disorders observed in elderly men.

\section{Acknowledgements}

The present study was part of the activities of the Associazione Sviluppo Studi Ormoni e Donna Atenei Toscani (ASSODAT), Pisa, Italy. We wish to thank L Catarsi, D Tognaccini and G Gagliardi for their technical assistance.

\section{References}

1 Robel P \& Baulieu EE. Neurosteroids: biosynthesis and function. Trends in Endocrinology and Metabolism 19945 1-8.

2 Mellon SH \& Deschepper CF. Neurosteroid biosynthesis: genes for adrenal steroidogenic enzymes are expressed in the brain. Brain Research 1993629 283-292.

3 Baulieu EE \& Robel P. Neurosteroids: a new brain function? Journal of Steroid Biochemistry and Molecular Biology 199037 395-403.

4 Majewska MD. Neurosteroids: endogenous bimodal modulators of the GABA-A receptor. Mechanism of action and physiological significance. Progress in Neurobiology 199238 379-395.

5 Mellon SH. Neurosteroids: biochemistry, modes of action, and clinical relevance. Journal of Clinical Endocrinology and Metabolism 199478 1003-1008.

6 Corpechot C, Young J, Calvel M, Wehrey C, Veltz JN, Touyer G, Mouren M, Prasad VVK, Banner C, Sjovall J, Baulieu EE \& Robel P. Neurosteroids: $3 \alpha$-hydroxy- $5 \alpha$-pregnan-20-one and its precursors in the brain, plasma, and steroidogenic glands of male and female rats. Endocrinology 1993133 1003-1009.

7 Palumbo MA, Salvestroni C, Gallo R, Ai-Li Guo, Genazzani AD, Artini PG, Petraglia F \& Genazzani AR. Allopregnanolone concentration in hippocampus of prepubertal rats and female rats throughout the estrous cycle. Journal of Endocrinological Investigation 199518 853-856.

8 Genazzani AR, Palumbo MA, de Micheraux AA, Artini PG, Criscuolo M, Ficarra G, Guo AL, Benelli A, Bertolini A, Petraglia F \& Purdy RH. Evidence for a role for the neurosteroid allopregnanolone in the modulation of reproductive function in female rats. European Journal of Endocrinology 1995133 375-380.

9 Roselli CE, Thornton JE \& Chambers KC. Age-related deficits in brain estrogen receptors and sexual behavior of male rats. Behavioral Neuroscience 1993107 202-209.

10 Baulieu EE. Studies on dehydroepiandrosterone (DHEA) and its sulphate during aging. Comptes Rendus de l'Academie des Sciences: la Vie des Sciences 1995318 7-11.

11 Baulieu EE. Dehydroepiandrosterone: a fountain of youth? Journal of Clinical Endocrinology and Metabolism 199681 3147-3151.

12 Purdy RH, Morrow AL, Moore PH \& Paul SM. Stress-induced elevations of $\gamma$-aminobutyric acid type A receptor-active steroids in the rat brain. Proceedings of the National Academy of Sciences of the USA 199188 4553-4557. 
13 Paul SM \& Purdy RH. Neuroactive steroids. FASEB Journal 19926 2311-2322.

14 Cheney DL, Uzunov D, Costa E \& Guidotti A. Gas chromatographic-mass fragmentographic quantitation of 3 alpha-hydroxy5 alpha-pregnan-20-one (allopregnanolone) and its precursors in blood and brain of adrenalectomized and castrated rats. Journal of Neuroscience $1995154641-4650$.

15 Marrone BL \& Karavolas HJ. Progesterone metabolism by the hypothalamus, pituitary, and uterus of aged rat. Endocrinology 1982 $111162-167$.

16 Holzbauer M, Birmingham MK, De Nicola AF \& Oliver JT. In vivo secretion of $3 \alpha$-hydroxy- $5 \alpha$-pregnan-20-one, a potent anaesthetic steroid, by the adrenal gland of the rat. Journal of Steroid Biochemistry 198522 97-102.

17 Ichikawa S, Sawada T, Nakamura Y \& Morioka H. Ovarian secretion of pregnane compounds during the estrous cycle and pregnancy in rats. Endocrinology 197494 1615-1620.

18 Sonntag WE, Golisek AG, Brodish A \& Eldridge JC. Diminished diurnal secretion of adrenocorticotropin (ACTH), but not corticosterone, in old male rats: possible relation to increased adrenal sensitivity to ACTH in vivo. Endocrinology 1987120 2308-2315.

19 Armario A, Rostrepo C, Hidalgo J \& Lopez-Calderon A. Differences in prolactin and LH responses to acute stress between peripuberal and adult male rats. Journal of Endocrinology 1987112 9-13.

20 Lauber ME \& Lichtensteiger W. Ontogeny of $5 \alpha$-reductase (type 1) messenger ribonucleic acid expression in rat brain: early presence in germinal zones. Endocrinology 1996137 2718-2730.

21 Barbaccia ML, Roscetti G, Trabucchi M, Concas A, Dazzi L, Purdy RI \& Biggio G. Brain allopregnanolone concentrations and GABA A receptor function in stressed rats. Society for Neuroscience 1995 Abstract 408.

22 Patchev VK, Shoaib M, Holsboer F \& Almeida OFX. The neurosteroid tetrahydroprogesterone counteracts corticotropinreleasing hormone-induced anxiety and alters the release and gene expression of corticotropin-releasing hormone in the rat hypothalamus. Neuroscience 199462 265-269.

23 Guo AL, Petraglia F, Criscuolo M, Ficarra G, Nappi RE, Palumbo MA, Trentini GP, Purdy RH \& Genazzani AR. Evidence for a role of neurosteroids in modulation of diurnal changes and acute stress-induced corticosterone secretion in rats. Gynecology Endocrinology 19959 1-7.

Received 12 June 1997

Accepted 10 November 1997 